\title{
Nutrientes, alimentación y actividad física como potenciadores del sistema inmune en tiempos de COVID-19
}

\author{
Nutrients, diet, and physical activity as enhancers of the immune system in times of COVID-19 \\ Marcelo Villagrán', María Adela Martínez-Sanguinetti², Fredy Díaz', Fanny Petermann-Rocha, ${ }^{3,4}$ Carlos Celis-Morales $3,4,5,6$
}

\section{Resumen}

El sistema inmune juega un rol fundamental en el mantenimiento de nuestra salud. Sin embargo, hay aspectos esenciales de nuestros estilos de vida que podrían ayudar a fortalecer la respuesta inmune frente a infecciones, tales como una buena alimentación y la práctica regular de actividad física. Mantener nuestro sistema inmune en un estado óptimo podría ser vital en situaciones de riesgo, como lo es la actual pandemia de COVID-19 que se desencadena a nivel mundial. Por ende, el objetivo de esta revisión narrativa de la literatura fue describir los beneficios inmunológicos asociados a la alimentación y actividad física con un enfoque especial al actual desafío sanitario del COVID-19. Particularmente, se ha abordado el efecto de la malnutrición por déficit y exceso, el rol de los macro y micronutrientes, la suplementación de micronutrientes, probióticos y patrones alimentarios sobre la funcionalidad del sistema inmune. En cuanto a la modulación inmunológica por la actividad física, hemos revisado la literatura científica con relación al efecto de la actividad física aeróbica y de los ejercicios de resistencia muscular sobre la respuesta inmunológica; la relación entre la actividad física, función pulmonar e infección por COVID-19, la interacción de la vacunación con actividad física y el riesgo de infección asociado a realizar actividad física en espacios cerrados.

Palabras clave: sistema inmune; COVID-19; alimentación; actividad física; ejercicio.

\begin{abstract}
The immune system plays an essential role in maintaining our health. However, there are essential aspects of our lifestyles that could help strengthen the immune response to infections, such as a good diet and regular physical activity. Keeping our immune system in an optimal state could be vital in risky situations, such as the current COVID-19 pandemic that is unleashed worldwide. Therefore, the objective of this narrative review of the literature was to describe the immunological benefits associated with diet and physical activity with a special focus on the current health challenge of COVID-19. In particular, the effect of excess and deficit malnutrition, the macro and micronutrients role, the supplementation of micronutrients, probiotics, and dietary patterns on the functionality of the immune system has been addressed. Regarding the immunological modulation by physical activity, we have reviewed the effect of aerobic physical activity and muscular resistance exercises on the immune response; the relationship between physical activity, lung function, and COVID-19 infection; the interaction of vaccination with physical activity, and the risk of infection associated with exercising indoors.
\end{abstract}

Keywords: immune system, COVID-19, diet, physical activity, exercise.

Fecha de envío: 2020-08-11 - Fecha de aceptación: 2020-12-23

(1) Departamento de Ciencias Básicas y Núcleo Científico Tecnológico para el Desarrollo Costero Sustentable. Universidad Católica de la Santísima Concepción, Concepción, Chile.

(2) Instituto de Farmacia, Facultad de Ciencias, Universidad Austral de Chile, Valdivia, Chile.

(3) Institute of Health and Wellbeing, University of Glasgow, Glasgow, United Kingdom.

(4) British Heart Foundation, Glasgow Cardiovascular Research Centre, Institute of Cardiovascular and Medical Sciences, University of Glasgow, Glasgow, United Kingdom.

(5) Laboratorio de Rendimiento Humano, Grupo de Estudio en Educación, Actividad Física y Salud (GEEAFyS), Universidad Católica del Maule, Talca, Chile.

(6) Centro de Investigación en Fisiología del Ejercicio (CIFE), Universidad Mayor. Chile.

Autor de correspondencia: marcelo.villagran@ucsc.cl. 
Villagrán et al.

\section{Introducción}

El actual escenario epidemiológico gatillado por el COVID-19 (del inglés Corona Virus Disease 19) está demandando conocer estrategias preventivas sustentadas en la evidencia científica que ayuden a enfrentar la actual pandemia. En este sentido, existe amplia evidencia que avala el rol de una alimentación saludable y la práctica regular de actividad física en la mantención y optimización de las funciones del sistema inmune. No obstante, las medidas de contención de la pandemia han influido negativamente en los estilos de vida de las personas como ha sido demostrado por diversos estudios a nivel mundial (Cheikh Ismail et al., 2020). Las medidas de aislamiento y distanciamiento social impuestos por la pandemia han impactado los estilos de vida en forma global, no solamente a nivel de la alimentación y actividad física; sino también generando aumento de estrés psicológico, deprivación de horas de sueño, disminución de exposición a la luz solar, entre otros. En relación a alimentación, un estudio en población italiana reportó que el confinamiento provocó una disminución de un $35,8 \%$ en el consumo de comidas saludables (frutas, verduras nueces y legumbres), mientras que un $48,6 \%$ de los individuos aumentó su peso corporal (Di Renzo et al., 2020). Sumado al desbalance alimentario, también se ha reportado aumento en el tiempo sedentario y disminución de la actividad física. Por consiguiente, los cambios negativos en los estilos de vida derivados de la pandemia podrían repercutir en la capacidad de respuesta inmunológica frente a una infección por COVID-19. La divulgación de mitos e información imprecisa sobre beneficios asociados a alimentos específicos, ciertos tipos de alimentación, uso de suplementos nutricionales y práctica de actividad física, amerita una revisión exhaustiva de la literatura científica. Por ende, el objetivo de esta revisión narrativa fue describir los beneficios inmunológicos asociados a la alimentación y actividad física con un enfoque especial en el actual desafío sanitario del COVID-19.

\section{Métodos}

Esta revisión narrativa recopiló información sobre los beneficios de la alimentación, nutrición, actividad física y ejercicio sobre el sistema inmune en humanos. Se consultaron los siguientes términos: immune system, COVID-19, diet, physical activity and exercise en las bases de datos de MEDLINE/PubMed, Cochrane Library, Web of Science, Scopus, Embase y SciELO. Para recabar información actualizada, también se incluyó la búsqueda de preprints en el buscador medRxiv. Los términos claves utilizados en la búsqueda fueron: nutrientes, dieta, alimentos, alimentación, sistema inmune, inmunología, ejercicio, actividad física, y deportes. La búsqueda se restringió a manuscritos publicados a partir de 1990, en idioma inglés y español.

\section{Generalidades del sistema inmune.}

El sistema inmune está compuesto por múltiples elementos que actúan coordinadamente para reconocer agentes infecciosos y montar una respuesta para su eliminación. La respuesta más temprana e inespecífica es la respuesta inmune innata, la cual depende de la integridad de las barreras epiteliales y la acción de moléculas antimicrobianas de amplio espectro como defensinas, catelicidinas, RNAsas de tipo A, lisozima, lactoferrina, entre otras (Hiemstra et al., 2016). Si el agente infeccioso eventualmente logra vulnerar la barrera, los componentes celulares de la inmunidad innata lo contrarrestarán mediante fagocitosis realizada por macrófagos y neutrófilos; o induciendo apoptosis de las células infectadas por virus mediante las células NK (del inglés natural killer) (Figura 1). Por otro lado, los fagocitos liberarán mediadores inflamatorios que gatillan efectos tanto sistémicos como localizados, incluyendo vasodilatación, aumento de permeabilidad vascular, quimiotaxis y fiebre, entre otros. Una segunda línea de defensa es la respuesta inmune adquirida, la cual responde con mayor efectividad a medida que el sistema inmune se expone sucesivamente a un determinado agente infeccioso. La respuesta inmune adquirida es específica contra un determinado agente infeccioso y lo reconoce a través de anticuerpos (inmunidad humoral) o células (inmunidad celular) (Figura 1) (Abbas, 2018). En ambos casos, la respuesta inmune comienza con una primera etapa de reconocimiento del antígeno presentado por las células presentadoras de antígeno (APC) en el contexto del complejo mayor de histocompatibilidad de clase 2 (MHC2) con el receptor de célula T (TCR). Solamente aquellas células T vírgenes capaces de reconocer el antígeno presentado activarán su proliferación, proceso autoestimulado por la liberación de interleuquina 2 (IL2). Como consecuencia de la multiplicación celular, se forma un clon de células con la misma especificidad antimicrobiana que la célula T original, las cuales posteriormente se diferencian en dos clases de células $T$ efectoras: células T colaboradoras que expresan los marcadores CD4 (cúmulo de diferenciación 4) y células T citotóxicas, las que expresan los marcadores CD8 en su superficie. Posteriormente, las células efectoras se distribuyen a los tejidos a través de la circulación sanguínea para localizar al agente infeccioso que tienen capacidad para reconocer $y$, una vez que interaccionan con él, activan una respuesta inmune para eliminarlos (Abbas, 2018). En el caso de las células T colaboradoras de subclase 2 (Th2), estas producirán IL4 (interleuquina 4), IL5 y IL13 involucradas en la respuesta ante parásitos de tipo helmíntico. Por su parte, las células T colaboradoras de subclase Th1, producirán interferón gama (INFg) y el ligando de superficie CD40 capaces de activar la capacidad fagocítica de los macrófagos y a los linfocitos B para producción de anticuerpos. Estas últimas células se diferenciarán en células plasmáticas que producen anticuerpos específicos contra el 


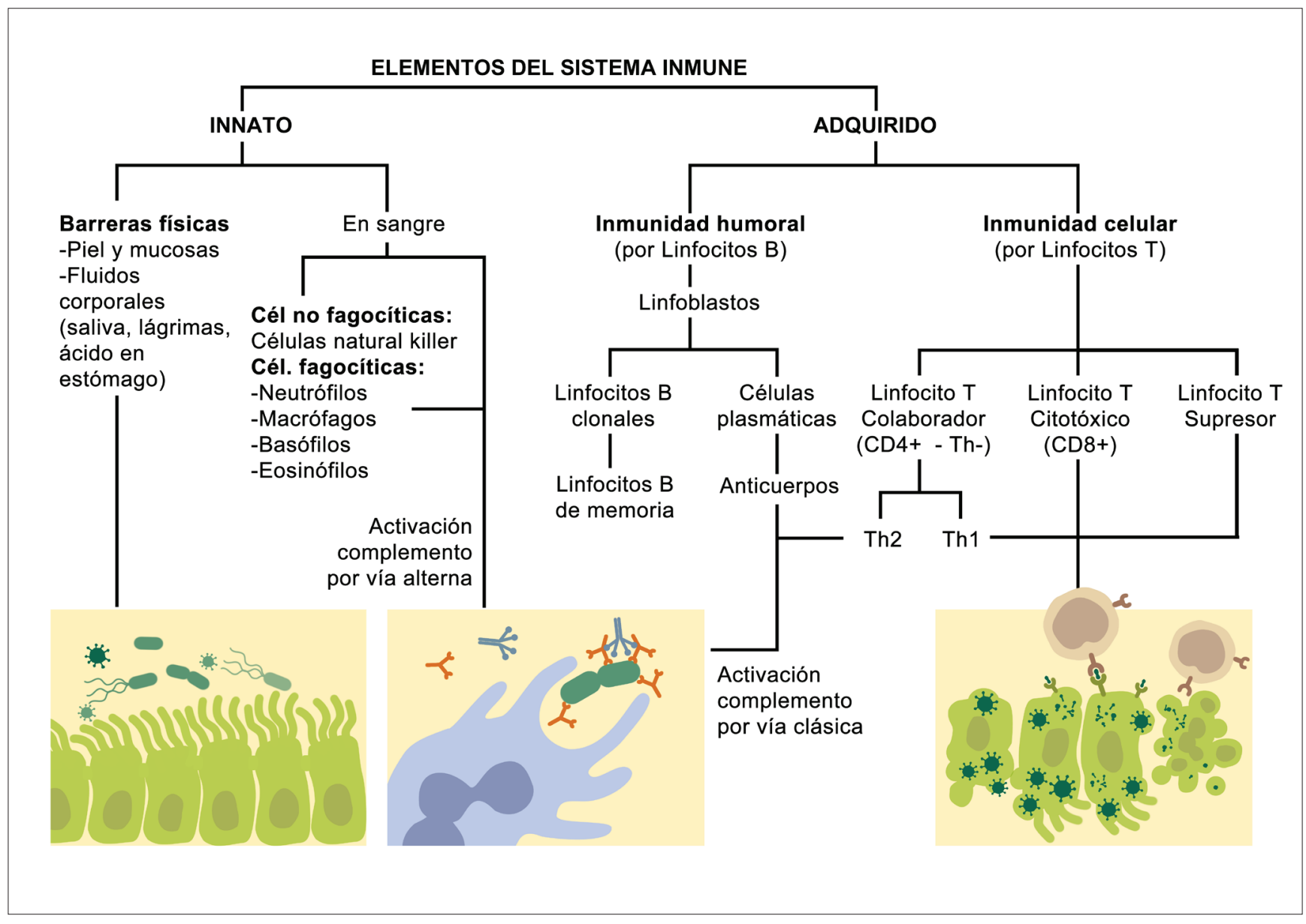

Figura 1: Elementos del sistema inmune innato y adquirido. CD4: cúmulo de diferenciación 4; CD8: cúmulo de diferenciación 8. Th1: linfocito T colaborador de tipo 1. Th2: linfocito T colaborador de tipo 2.

microorganismo. A su vez, los anticuerpos se unirán específicamente al microorganismo lo cual facilitará la fagocitosis (opsonización), bloquearán su capacidad para infectar a otras células y además activarán el sistema del complemento, involucrado en la promoción de la fagocitosis y la lisis del microorganismo (Abbas, 2018). Por su parte, los linfocitos T citotóxicos reconocerán aquellas células que han sido infectadas por virus, ya que estas presentan antígenos virales asociados a proteínas del MHC I en su superficie. Luego de establecer una estrecha interacción con las células infectadas, el linfocito T citotóxico liberará perforinas y granzimas que inducirán apoptosis de la célula infectada. Finalmente, se reestablece la homeostasis por la apoptosis de las células efectoras, pero prevalecerá un pequeño número de células ByT de memoria que otorgarán inmunidad frente a una exposición recurrente (Abbas, 2018).

La acción coordinada de los elementos de la inmunidad innata y adquirida funcionan eficientemente para mantenernos protegidos de los innumerables agentes infecciosos con los que interaccionamos diariamente (Figura 2). Sin embargo, algunos de ellos presentan propiedades específicas que entorpecen y/o evaden los mecanismos de defensa inmunitaria. Para el caso del COVID-19, una caracterización clínica de 41 pacientes hospitalizados en Wuhan, China, durante enero de 2020, describió que un 32\% de los pacientes ingresaron a la unidad de cuidados intensivos presentaron niveles extraordinariamente altos de IL2, IL7, IL10, factor estimulante de colonias de granulocitos (GCSF), proteína inducida por proteína inducida por interferón gamma 10, proteína quimiotáctica de monocitos ( $\mathrm{MCP} 1)$, proteína inflamatoria de macrófagos 1A (MIP1A) y factor de necrosis tumoral a (TNF-a) (Huang et al., 2020). Este fenómeno, denominado "tormenta de citoquinas", provoca un estado hiperinflamatorio que también ha sido observado en las infecciones causadas por otros coronavirus de alta patogenicidad como SARS-CoV y MERS-CoV, para los cuales se cuenta con mayor evidencia (Singhal, 2020). Dichos estudios revelan que el estado hiperinflamatorio inducido por SARS-CoV y MERS-CoV conduce a acumulación de macrófagos y neutrófilos en el tejido pulmonar, degeneración del epitelio y endotelio pulmonares por apoptosis, respuestas subóptimas de linfocitos Ty dificultad respiratoria aguda, que conduce a una falla multiorgánica (Singhal, 2020). 


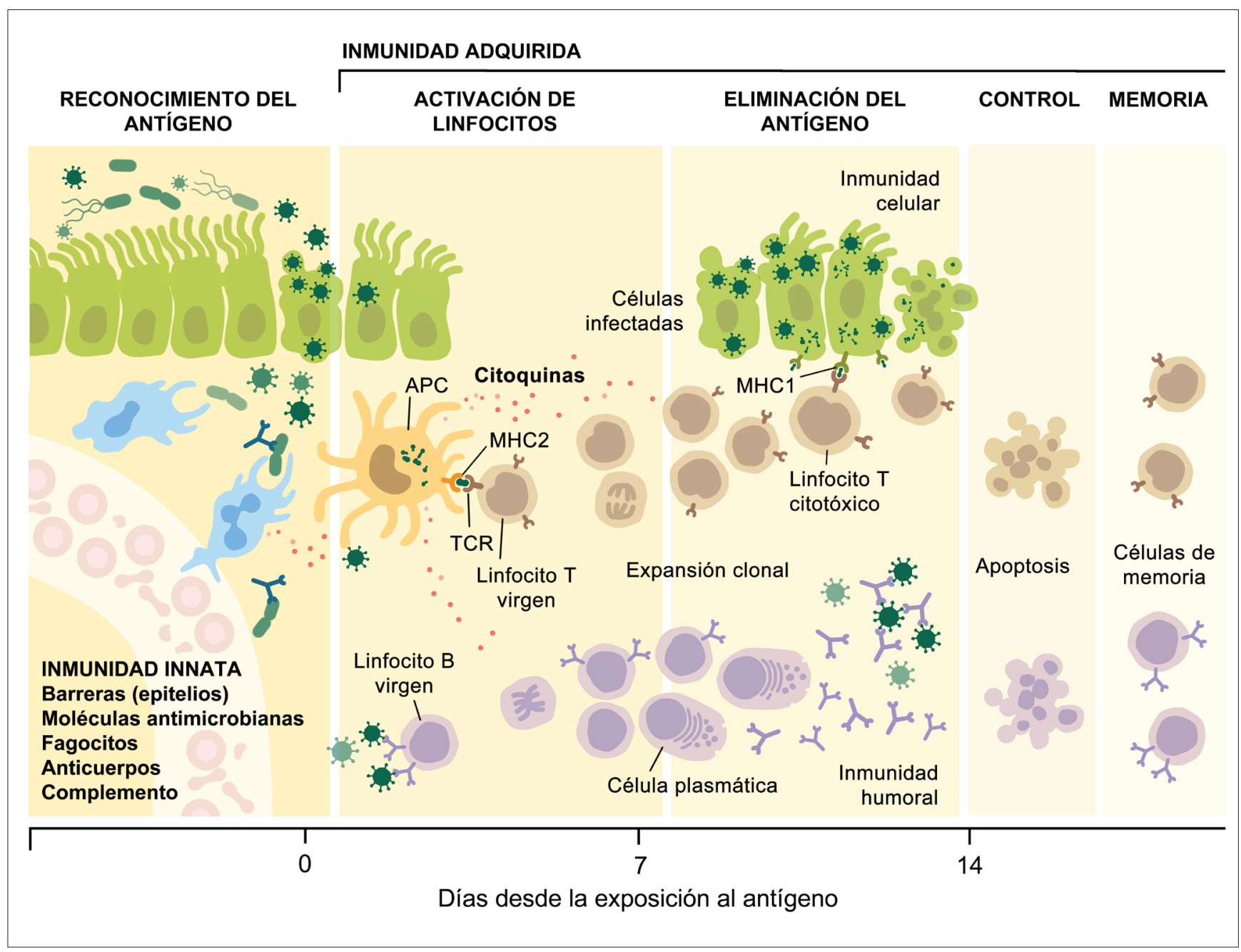

Figura 2: Etapas de en la acción de la inmunidad adquirida. APC: célula presentadora de antígenos; TCR: receptor de célula T; MHC1: complejo mayor de histocompatibilidad de tipo 1; MHC2: complejo mayor de histocompatibilidad de tipo 2.

\section{Alimentación, nutrición y sistema inmune}

Una alimentación balanceada es un factor importante para asegurar un óptimo funcionamiento del sistema inmune. Los nutrientes provenientes de nuestra alimentación participan directamente en la producción de citoquinas, linfocitos B y T, macrófagos y leucocitos. Deficiencias en macronutrientes (como arginina) y micronutrientes (como zinc y vitamina B12) pueden repercutir negativamente sobre las defensas del organismo, junto con alterar su respuesta y capacidad para combatir infecciones causadas por agentes patógenos, ya sea por microorganismos o por virus (Mahmoudi, 2019). Una infección desencadena múltiples señales y respuestas inflamatorias para atacar al agente infeccioso en nuestro organismo. Las personas con bajo aporte energético, desnutrición y dietas desbalanceadas, presentarán mayor inmunodeficiencia y mayor riesgo de infecciones por diferentes patógenos, especialmente influenza y coronavirus. Una malnutrición por déficit genera cambios en la respuesta innata y adaptativa, junto con afectar directamente la producción de anticuerpos por las células $\mathrm{B}$, generación de monocitos y linfocitos; y puede reducir el tamaño del timo (Gardner, 2014; Mahmoudi, 2019). Además, la infección podría tener efectos perjudiciales sobre el estado nutricional que podría conducir a un ciclo perpetuado de desnutrición e infección, generando una interacción sinérgica entre ambos; es decir, la infección podría agravar la malnutrición y la malnutrición agravar la infección. Además, este ciclo favorecerá la pérdida de peso corporal, falta de apetito, mala cicatrización de heridas y promoverá otras infecciones (Mahmoudi, 2019). Lo anterior se presenta en mayor medida en personas mayores que son un grupo de alto riesgo, tanto para malnutrición por déficit como para infección, condiciones que podrían gatillar un mayor riesgo de morbilidad y mortalidad en este grupo etario. Durante la pandemia de COVID-19, Li et al. reportaron que un 80,2\% de los pacientes mayores de 65 años hospitalizados por COVID-19 
en un hospital de Wuhan presentaban riesgo de malnutrición o ya se encontraban malnutridos (Li et al., 2020). Por otro lado, la malnutrición incrementa el riesgo de fragilidad, condición que ha demostrado incrementar en 2,7 veces el riesgo de hospitalización o muerte por COVID-19 (Petermann-Rocha et al., 2020).

Lo anterior no implica que las personas requerirán consumir un exceso de energía para mejorar la respuesta inmune, ya que este exceso se acompañará de estrés crónico asociado a exceso de nutrientes y energía (Mahmoudi, 2019). Esto último desencadenará procesos inflamatorios generalizados, lo que contribuirá a enfermedades inmunometabólicas asociadas, tales como, diabetes mellitus tipo 2, asma, enfermedades cardiovasculares, enfermedades degenerativas y cáncer (Mahmoudi, 2019). En la obesidad, el exceso de adiposidad induce a una inflamación crónica de bajo grado, con mayor expresión y producción de angiotensinógenos, enzima convertidora de angiotensina 2 (ACE 2), leptina, citoquinas proinflamatorias (TNF-a, IL-6 y IL-1 $\beta$ ), comprometiendo el sistema inmunológico y los mecanismos de defensa del huésped, aumentando así la susceptibilidad a infecciones respiratorias agudas graves, en especial la producida por el virus SARS-CoV-2 (Morais et al., 2020). En la actualidad se cuenta con los primeros estudios (en tiempo de pandemia) que sugieren que las personas con obesidad tienen más riesgo de desarrollar una enfermedad grave ocasionada por COVID-19, con mayor riesgo de hospitalización, cuidados intensivos, ventilación mecánica y/o muerte; independiente de otras comorbilidades. Esto fue confirmado por un estudio prospectivo en 5279 pacientes con COVID-19 desarrollado en la ciudad de Nueva York, en Estados Unidos, donde el 34,3\% y $39,5 \%$ de los pacientes que necesitaron ser hospitalizados por estar en estado crítico, presentaban sobrepeso y obesidad, respectivamente (Petrilli et al., 2020). Otro estudio liderado por Ho et al. en el Biobanco de Reino Unido (UK Biobank), confirmó también que la obesidad es un factor de riesgo para el desarrollo de COVID-19, ya que, personas con sobrepeso y obesidad presentaban mayor riesgo de desarrollar síntomas severos producido por COVID-19 (44\% y $97 \%$, respectivamente) (Figura 3) (Ho, 2020).

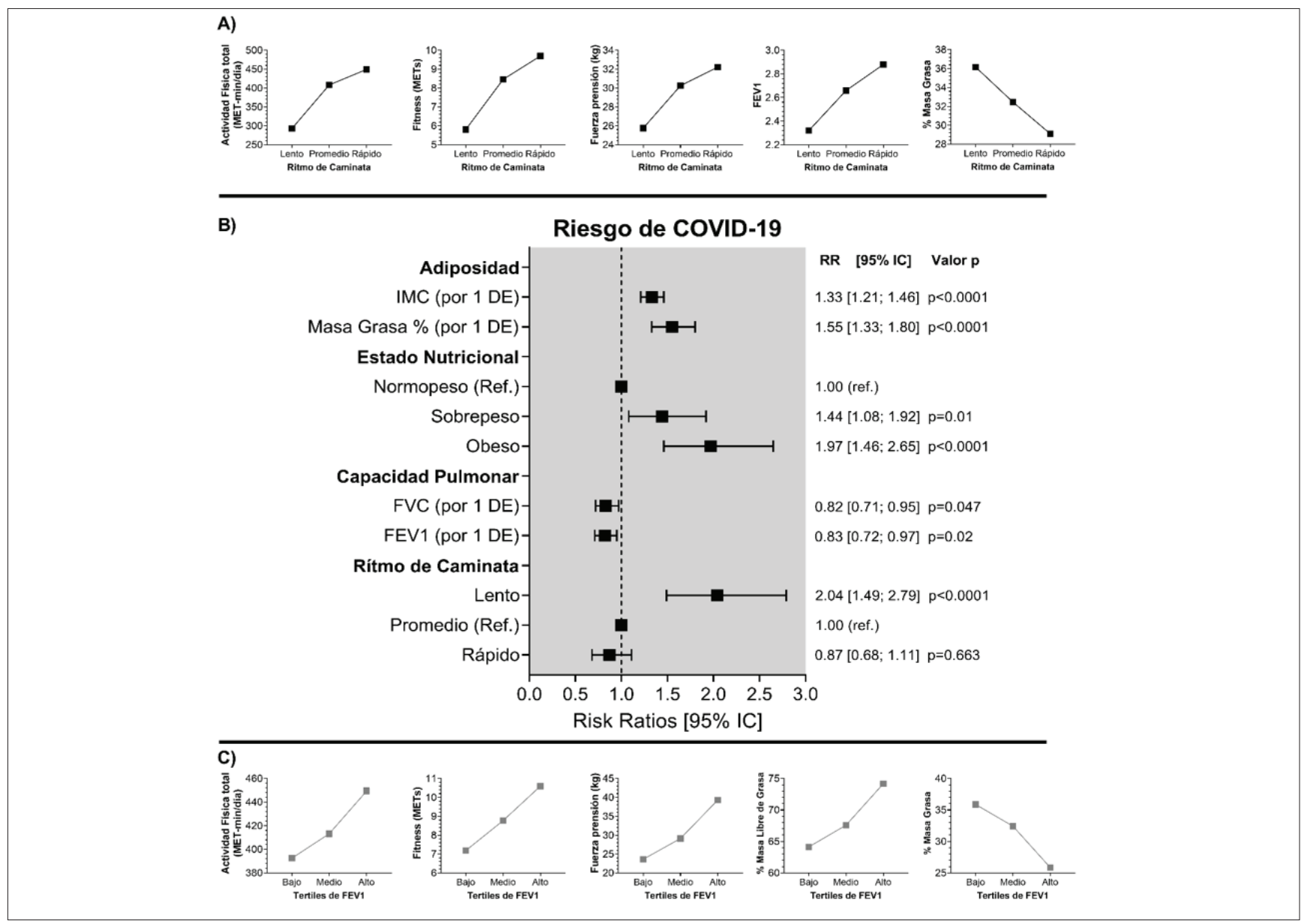

Figura 3: Factores de riesgo asociados a COVID-19. Los resultados son presentados como riesgo relativo y sus $95 \%$ de intervalos de confianza para la Figura B. Los datos de la figura A y C son presentados como promedios según categorías de ritmo de caminata y tertiles de capacidad funcional pulmonar (FEV1) según actividad física, fitness cardiorrespiratorio, fuerza muscular y adiposidad. Estos datos fueron extraídos y ajustados de Ho et al. (2020) y se basan en población británica. Desviación estándar (DE). (Steell et al., 2019). 
En términos de macronutrientes, un déficit de proteínas afecta directamente las funciones de barreras epiteliales, con una disminución de la síntesis de anticuerpos en las mucosas, favoreciendo la entrada de microorganismos. En relación con los ácidos grasos, estos cumplen una función estructural en todas las membranas celulares. Particularmente, los ácidos grasos poliinsaturados omega 3 (PUFAs por su sigla en inglés), afectan directamente la función de las células inmunes, dado que son los precursores de prostaglandinas y leucotrienos (Tabla 1) (Weyh et al., 2020).

\section{Tabla 1: Nutrientes y su función inmunitaria.}

\begin{tabular}{|c|c|c|c|}
\hline Nutriente & Función inmunitaria & Fuente alimentaria & Suplementación \\
\hline $\begin{array}{l}\text { Metionina, cisteína } \\
\text { y arginina }\end{array}$ & $\begin{array}{l}\text { La metionina es sustrato de enzimas antioxidantes } \\
\text { como la metionina sulfóxido reductasa A. Metionina y } \\
\text { cisteína son precursores de la biosíntesis de glutatión, } \\
\text { necesario para contrarrestar el estrés oxidativo producido } \\
\text { en procesos inflamatorios. Arginina es un precursor del } \\
\text { óxido nítrico, un efector de la citotoxicidad mediada } \\
\text { por macrófagos y regula la proliferación de Th1. }\end{array}$ & $\begin{array}{l}\text { Nueces, carnes, mariscos, pescado, huevos, } \\
\text { legumbres y productos lácteos. }\end{array}$ & - \\
\hline $\begin{array}{l}\text { Ácidos grasos } \\
\text { poliinsaturados } \\
\text { Omega-3 }\end{array}$ & $\begin{array}{l}\text { Efectos antiinflamatorios a través de sus efectos sobre la } \\
\text { acción de los leucocitos, la producción de eicosanoides } \\
\text { y la proliferación de células T. }\end{array}$ & $\begin{array}{l}\text { Pescados altos en grasa, fuentes vegetales } \\
\text { como semillas de lino y cáñamo. }\end{array}$ & $\begin{array}{l}\text { Posibles efectos antiinflamatorio e inmuno-re- } \\
\text { gulador post-ejercicio, pero resultados no } \\
\text { concluyentes debido a bajo poder estadístico. }\end{array}$ \\
\hline $\begin{array}{l}\text { Vitamina A } \\
\text { (retinol) } \\
\text { Beta-caroteno }\end{array}$ & $\begin{array}{l}\text { El ácido retinoico (metabolito biológicamente activo } \\
\text { de la vitamina A), regula la maduración de precursores } \\
\text { de leucocitos. } \\
\text { La deficiencia de vitamina A aumenta la susceptibilidad } \\
\text { a infecciones y enfermedades autoinmunes. }\end{array}$ & $\begin{array}{l}\text { Vitamina A preformada: origen animal (hígado } \\
\text { y riñón, pescados grasos, aceite de pescado, } \\
\text { mantequilla, leche entera, queso, yema de } \\
\text { huevo, leche materna). } \\
\text { Beta-caroteno (provitamina A): } \\
\text { Presente en frutas y verduras amarillos, } \\
\text { naranjos y rojos (zanahoria, camote, mango, } \\
\text { tomate, pimiento rojo, papaya). Hortalizas de } \\
\text { color verde oscuro: espinacas, acelgas, brócoli. } \\
\text { Se recomienda consumir entre } 375 \text { a } 600 \mu g \\
\text { ER/día (RDA) }\end{array}$ & $\begin{array}{l}\text { La suplementación disminuye el riesgo mor- } \\
\text { bi-mortalidad por enfermedades infecciosas, } \\
\text { pero no es beneficiosa en la neumonía. Se } \\
\text { deben considerar que a altas dosis la vitamina } \\
\text { A presenta toxicidad. }\end{array}$ \\
\hline $\begin{array}{l}\text { Vitamina D } \\
\text { (calciferol) }\end{array}$ & $\begin{array}{l}\text { Suprime la autoinmunidad y tiene efecto antiin- } \\
\text { flamatorio. Promueve diferenciación de las células } \\
\text { dendríticas, reduce la actividad de células Th17 y la } \\
\text { secreción citoquinas pro-inflamatorias. El exceso de } \\
\text { vitamina D es tóxica. }\end{array}$ & $\begin{array}{l}\text { Se encuentra en la grasa de ciertos productos } \\
\text { animales (huevos, queso, leche, hígado, man- } \\
\text { tequilla, aceite de bacalao, pescados grasos) } \\
\text { y margarina. } \\
\text { Se recomienda consumir entre } 5 \text { a } 15 \mu \mathrm{g} / \mathrm{d} \text { día (RDA), } \\
\text { variando su recomendación por sexo y edad. Se } \\
\text { obtiene también por exposición a la luz solar. }\end{array}$ & $\begin{array}{l}\text { La suplementación con vitamina } D \text { en personas } \\
\text { con deficiencia, reduce las infecciones agudas } \\
\text { del tracto respiratorio. Se necesitan estudios } \\
\text { de mayor poder estadístico para confirmarlo } \\
\text { de forma inequívoca. }\end{array}$ \\
\hline $\begin{array}{l}\text { Vitamina E } \\
\text { (tocoferoles) }\end{array}$ & $\begin{array}{l}\text { Protege a los ácidos grasos poliinsaturados y la LDL } \\
\text { de la oxidación por radicales libres liberados en pro- } \\
\text { cesos inflamatorios. Confiere protección contra varias } \\
\text { enfermedades infecciosas. }\end{array}$ & $\begin{array}{l}\text { Aceites vegetales (soya, girasol, maíz, germen de } \\
\text { trigo), margarinas, frutos secos (avellanas, almen- } \\
\text { dras, maní, nueces), cereales de grano entero. } \\
\text { Se recomienda a los adultos consumir } 8 \text { y } 10 \mathrm{mg} \\
\text { ET/día, para mujeres y adultos, respectivamente. }\end{array}$ & $\begin{array}{l}\text { La suplementación con vitamina E puede } \\
\text { aumentar la respuesta inmune humoral, tales } \\
\text { como producción de anticuerpos, actividad } \\
\text { macrofágica y fagocitosis. } \\
\text { En adultos mayores, reduce las infecciones al } \\
\text { tracto respiratorio. }\end{array}$ \\
\hline $\begin{array}{l}\text { Vitamina C } \\
\text { (ácido ascórbico) }\end{array}$ & $\begin{array}{l}\text { Potente antioxidante con propiedades antibacterianas, } \\
\text { antivirales, antiparasitarias, antifúngicas. Se acumula en } \\
\text { las células fagocíticas mejorando su quimiotaxis, fago- } \\
\text { citosis y generación de especies reactivas de oxígeno. } \\
\text { Mejora la diferenciación y la proliferación de las células } \\
\text { ByT. Su deficiencia severa se asocia con deficiencias en } \\
\text { la inmunidad y mayor susceptibilidad a infecciones. }\end{array}$ & $\begin{array}{l}\text { Frutas frescas (cítricos, kiwi, mango, papaya), } \\
\text { hortalizas frescas (hojas verdes, tomates, } \\
\text { pepinos), camote. } \\
\text { Se recomienda consumir entre } 40 \text { a } 90 \mathrm{mg} / \text { día } \\
\text { (RDA), variando su recomendación por sexo y } \\
\text { edad. Se debe aumentar a } 120 \mathrm{mg} / \text { día durante la } \\
\text { lactancia, lo cual se alcanza con } 5 \text { frutas frescas. }\end{array}$ & $\begin{array}{l}\text { La suplementación con vitamina C parece útil } \\
\text { para prevenir y tratar infecciones respiratorias } \\
\text { y sistémicas; en el tratamiento de infecciones } \\
\text { se requiere suplementos con dosis más altas } \\
\text { que las administradas en la prevención, pero } \\
\text { los resultados no son concluyentes. }\end{array}$ \\
\hline $\begin{array}{l}\text { Vitamina } \mathrm{B}_{9} \\
\text { (Ácido fólico) }\end{array}$ & $\begin{array}{l}\text { Contribuye al mantenimiento de la homeostasis inmu- } \\
\text { nológica. Su deficiencia reduce la cantidad de las células } \\
\text { T reguladoras en el intestino delgado, aumentando la } \\
\text { susceptibilidad a la inflamación intestinal. }\end{array}$ & $\begin{array}{l}\text { Fuente rica (>100 } \mu \mathrm{g} / \text { porción): coles de Bru- } \\
\text { selas, espinacas. } \\
\text { Buena fuente }(50-100 \mu \mathrm{g} / \text { porción): cereales y } \\
\text { harinas fortificadas, brócoli, repollo, coliflor, } \\
\text { garbanzos, porotos verdes, lentejas, riñón, } \\
\text { Fuente moderada ( } 15-50 \mu \mathrm{g} / \text { porción): papas, la } \\
\text { mayoría de las verduras, frutas y frutos secos, } \\
\text { arroz integral, grano integral, pastas, avena, } \\
\text { salvado de trigo, cereales para el desayuno, } \\
\text { queso, leche yogur, huevos, salmón, carne de } \\
\text { vacuno. Alimentos fortificados } \\
\text { La FAO/OMS recomienda a los adultos una } \\
\text { ingesta de } 400 \mu \mathrm{g} / \text { día de folatos (RDA). }\end{array}$ & $\begin{array}{l}\text { La suplementación con vitamina } \mathrm{B}_{9} \text { puede } \\
\text { aumentar la inmunidad innata en personas } \\
\text { mayores. }\end{array}$ \\
\hline
\end{tabular}




\begin{tabular}{|c|c|c|c|}
\hline $\begin{array}{l}\text { Vitamina } \mathrm{B}_{6} \\
\text { (Piridoxina) }\end{array}$ & $\begin{array}{l}\text { Su deficiencia se asocia al desarrollo de enfermedades } \\
\text { inflamatorias, como alergia y artritis reumatoide, como } \\
\text { también con disfunción neuronal. } \\
\text { Juega un rol importante en la inmunovigilancia, au- } \\
\text { mentando la infiltración de linfocitos hacia el tejido } \\
\text { intestinal, y contribuyendo a la protección inmunológica. }\end{array}$ & $\begin{array}{l}\text { Muy común en alimentos de origen animal } \\
\text { y vegetal. Carnes, pollo, pescado, granos } \\
\text { integrales, cereales fortificados, frutos secos, } \\
\text { plátanos, camote, paltas. } \\
\text { La FAO/OMS recomienda a los adultos consumir } \\
1,3-1,7 \mathrm{mg} / \text { día de vitamina } \mathrm{B}_{6}(\mathrm{RDA}) \text {. }\end{array}$ & $\begin{array}{l}\text { La suplementación con vitamina } \mathrm{B}_{6} \text { ayuda a } \\
\text { restaurar la inmunidad celular, puede mejorar } \\
\text { la maduración de linfocitos y } \\
\text { crecimiento y aumentar el número de } \\
\text { Linfocitos } T \text { y en grandes dosis puede mejorar } \\
\text { la respuesta inmune } \\
\text { de pacientes críticos. }\end{array}$ \\
\hline $\begin{array}{l}\text { Vitamina } B_{12} \\
\text { (Cobalamina) }\end{array}$ & $\begin{array}{l}\text { Contribuye a la respuesta inmune a través de la } \\
\text { estimulación de las funciones de las células T CD8+ } \\
\text { y células NK. }\end{array}$ & $\begin{array}{l}\text { Solo en alimentos de origen animal. Carne y } \\
\text { productos cárnicos, huevos, leche, pescados } \\
\text { y alimentos fortificados (cereales para el } \\
\text { desayuno). } \\
\text { La FAO/OMS recomienda a los adultos consumir } \\
2,4 \text { Mg/día de Vit. } B_{12} \text { (RDA). }\end{array}$ & $\begin{array}{l}\text { La suplementación con vitamina } B_{12} \text { aumenta el } \\
\text { número de células involucradas en la respuesta } \\
\text { inmune celular. }\end{array}$ \\
\hline Hierro & $\begin{array}{l}\text { Estimula la proliferación de los linfocitos. Su deficiencia } \\
\text { se asocia con disminución de la función y recuento de } \\
\text { linfocitos T, así como también una disminución en la } \\
\text { respuesta inmune innata. } \\
\text { El hierro es esencial para el crecimiento, sobreviven- } \\
\text { cia y de microorganismos. Durante una infección el } \\
\text { hierro es almacenado intracelularmente para limitar } \\
\text { la proliferación de patógenos. }\end{array}$ & $\begin{array}{l}\text { Mayor biodisponibilidad: carnes, pescado, } \\
\text { huevos, hígado, vísceras, menor proporción } \\
\text { lácteos. Menor biodisponibilidad: legumbres, } \\
\text { nueces, cereales integrales o de grano entero. } \\
\text { Se recomienda consumir entre } 8 \text { a } 18 \mathrm{mg} / \\
\text { día (RDA), variando su recomendación por } \\
\text { sexo y edad. }\end{array}$ & $\begin{array}{l}\text { Se postula que podría mejorar la inmunidad a } \\
\text { enfermedades infecciosas. Sin embargo, una } \\
\text { suplementación no dirigida, puede aumentar } \\
\text { la disponibilidad de hierro para crecimientos } \\
\text { de patógenos. }\end{array}$ \\
\hline Zinc & $\begin{array}{l}\text { Posee efecto antiviral junto con regular la activación } \\
\text { de respuesta de fase aguda. Su déficit se asocia con } \\
\text { disminución en la proliferación de linfocitos B y T, } \\
\text { disminución de la función de células NK, disminución } \\
\text { de la maduración de células T y afecta integridad de } \\
\text { barreras epiteliales. }\end{array}$ & $\begin{array}{l}\text { Mariscos, hígado, legumbres, frutos secos, } \\
\text { carnes, pescado, huevos y lácteos. } \\
\text { Se recomienda consumir } 8 \text { y } 11 \mathrm{mg} / \text { día (RDA), } \\
\text { para mujeres y hombres, respectivamente. }\end{array}$ & $\begin{array}{l}\text { La literatura ha reportado mejores resultados } \\
\text { en neumonía, malaria y síntomas diarreicos } \\
\text { en personas suplementadas. } \\
\text { También se ha descrito un efecto en un mayor } \\
\text { número de células T citotóxicas, aumento de } \\
\text { la citotoxicidad de las células NK y reducción } \\
\text { de la cantidad de células Thelper activadas (lo } \\
\text { que contribuye a la inmunidad). }\end{array}$ \\
\hline Cobre & $\begin{array}{l}\text { Actúa como cofactor en enzimas dependientes de cobre } \\
\text { requeridas como defensa antioxidante. Su déficit se } \\
\text { encuentra asociado con una disminución en el número } \\
\text { de neutrófilos circulantes, disminución de anticuerpos } \\
\text { y disminución de la actividad de las células NK. }\end{array}$ & $\begin{array}{l}\text { Frutos secos, cereales, carnes. } \\
\text { Se recomienda consumir } 900 \mu \mathrm{g} / \mathrm{día} \text { (RDA). }\end{array}$ & $\begin{array}{l}\text { En niños con deficiencia, incrementa la fago- } \\
\text { cítica de macrófagos. Sin embargo, un exceso } \\
\text { de cobre podría influenciar negativamente la } \\
\text { respuesta inmune. }\end{array}$ \\
\hline Selenio & $\begin{array}{l}\text { Forma parte de seleno-proteínas que ejercen función } \\
\text { antioxidante. Estimula la proliferación linfocitaria y } \\
\text { células NK junto con la Vitamina E. Su déficit se asocia } \\
\text { con aumento de daño oxidativo en células inmunes, } \\
\text { alteración en la producción de anticuerpos junto con una } \\
\text { mayor susceptibilidad infecciones bacterianas y virales. }\end{array}$ & $\begin{array}{l}\text { Carne, pescado, mariscos, cereales, huevo, } \\
\text { semillas de girasol, nueces de Brasil, y frutas } \\
\& \text { verduras (según la cantidad de selenio inor- } \\
\text { gánico presente en el suelo). Se recomienda } \\
\text { consumir } 55 \mu \mathrm{g} / \text { día (RDA). }\end{array}$ & $\begin{array}{l}\text { En personas con deficiencia, mejora la inmunidad } \\
\text { mediada por células y aumenta la respuesta } \\
\text { inmune a los virus. Suplementación de } 50 \\
\text { a } 100 \mu \mathrm{g} / \text { día por } 15 \text { semanas incrementó la } \\
\text { producción de interferón. } \\
\text { Sin embargo, pueden empeorar el asma alérgico. }\end{array}$ \\
\hline Magnesio & $\begin{array}{l}\text { Componente de enzimas. Su déficit se asocia con } \\
\text { aumento de los niveles de interleuquinas y TNF. Influye } \\
\text { en la citotoxicidad de las células T y funcionamiento } \\
\text { de moléculas de adhesión. }\end{array}$ & $\begin{array}{l}\text { Vegetales verdes, granos enteros, carnes. Se } \\
\text { recomienda consumir entre } 310 \text { a } 420 \mathrm{mg} / \\
\text { día (RDA), variando su recomendación por } \\
\text { sexo y edad. }\end{array}$ & $\begin{array}{l}\text { Entre sus efectos se ha reportado una reducción } \\
\text { en la activación leucocitaria y reducción del } \\
\text { daño oxidativo al ADN } \\
\text { de linfocitos de sangre periférica en } \\
\text { atletas y hombres jóvenes sedentarios. }\end{array}$ \\
\hline Manganeso & $\begin{array}{l}\text { Cofactor de enzimas con actividad antioxidante. Su } \\
\text { déficit se asocia con disminución de la actividad de } \\
\text { la enzima antioxidante linfocitaria. }\end{array}$ & $\begin{array}{l}\text { Cereales, té, verduras. Se recomienda consumir } \\
1,8 \text { y } 2,3 \mathrm{mg} / \mathrm{día}(\mathrm{IA}) \text {, para mujeres y hombres, } \\
\text { respectivamente. }\end{array}$ & $\begin{array}{l}\text { Su uso excesivo podría causar deficiencia de } \\
\text { hierro, lo que a su vez gatillaría deficiencias en } \\
\text { el sistema inmune asociados a déficit de hierro. }\end{array}$ \\
\hline
\end{tabular}

RDA: consumo diario recomendado; IA: ingesta adecuada.

En términos de micronutrientes, si bien una dieta equilibrada es necesaria para una correcta función del sistema inmune, estudios han identificado micronutrientes claves, cuyas deficiencias alteran la respuesta inmune. Se destaca el rol de las vitaminas $A, B_{6}, B_{9}$ (ácido fólico), $B_{12}$ C, D y E y minerales como hierro, zinc y selenio (Gardner, 2014; Mahmoudi, 2019). La función de estos micronutrientes en nuestro sistema inmune, y su fuente alimentaria, se resume en la Tabla 1. Por otro lado, la suplementación de micronutrientes es cada vez más frecuente y se ha demostrado que suplementar la dieta con micronutrientes deficientes mejora funciones inmunes específicas (Tabla 1). Existen estudios que sugieren considerar suplementos de micronutrientes solo en personas que tienen una ingesta diaria inadecuada de micronutrientes (Gombart et al., 2020). En este contexto, la suplementación de micronutrientes podría ser beneficiosa para el sistema inmune cuando existen deficiencias moderadas o severas (Gombart et al., 2020). Estudios recientes sobre el manejo terapéutico de COVID-19, sugieren que en aquellos pacientes con deficiencias nutricionales se les brinde apoyo nutricional con suplementos de micronutrientes, lo que puede ayudar a obtener un mejor resultado a los tratamientos contra la enfermedad (Junaid et al., 2020). Sin embargo, existe controversia sobre posibles efectos adversos del uso excesivo de suplementos,

\section{ARS MEDICA Revista de Ciencias Médicas Volumen 45 número 4 año 2020}


especialmente en personas sanas (Gombart et al., 2020). Algunos estudios han mostrado resultados inconsistentes, probablemente, por sus diseños o poblaciones utilizadas (Gombart et al., 2020).

Por otra parte, los probióticos también destacan por su efecto modulador del sistema inmune local y sistémico (Weyh et al., 2020). Los probióticos (microorganismos vivos), cuando se consumen en cantidades adecuadas, regulan la microbiota intestinal y se asocian aumentos de marcadores de función inmunológica; como la producción de citoquinas, aumento de la actividad citotóxica de células NK, incremento de los niveles de inmunoglobulina $A$ y mayor resistencia a infecciones (Hill et al., 2014). Por otro lado, los probióticos contribuyen a modular la respuesta inflamatoria gatillada por la infección (Weyh et al., 2020). No todos los microorganismos que se incorporan en los alimentos son probióticos; deben mostrar propiedades no patógenas, capacidad de sobrevivir en su tránsito a través del tracto digestivo, adherencia al epitelio intestinal, colonización en el intestino, para poder ejercer sus efectos beneficiosos en el colon (Hill et al., 2014). Las cepas más estudiadas de probióticos pertenecen a los géneros Lactobacillusy Bifidobacterium, y se consumen principalmente a través de la incorporación en productos lácteos fermentados. Estudios controlados con probióticos han observado un mejoramiento de la función inmunitaria; sin embargo, las respuestas varían según la cepa y especie de microorganismos probióticos o mezclas de probióticos utilizados, como también en el grupo de la población estudiado (Mak et al., 2020). Por lo anterior, no se puede generalizar acerca del rol que ejercen los probióticos en la resistencia a infecciones en los distintos grupos de la población.

Una revisión reciente entregó evidencia sobre el uso de probióticos en el tratamiento del COVID-19, demostrando una modesta eficacia en la reducción de diarrea asociada al uso de antibióticos e incidencia y duración de infecciones virales del tracto respiratorio, siendo poco probable que tengan un efecto directo sobre el desarrollo de COVID-19. En consecuencia, la evidencia actual es insuficiente para recomendar el uso de probióticos para contrarrestar los efectos del COVID-19 (Mak et al., 2020).

Finalmente, los "prebióticos", componentes de la dieta no digeribles por el huésped, son fermentados selectivamente en el colon, estimulando el desarrollo de probióticos (Hill et al., 2014). Los prebióticos se diferencian de la fibra dietética, por su selectividad para ciertos microorganismos; por ejemplo, el consumo de prebióticos como inulina, estimulan el desarrollo de Bifidobacterium (Hill et al., 2014). La combinación de probióticos + prebióticos se denomina "simbióticos"y generalmente se adicionan combinadamente en los alimentos, siendo sus efectos inmunomoduladores más potentes, en especial cuando se administran en etapas tempranas de la vida (Frei et al., 2015).

\section{Patrones alimentarios y sistema inmune}

Dada la estrecha relación entre la homeostasis del sistema inmune y el consumo de nutrientes específicos, resulta lógico que algunos patrones alimentarios puedan estar asociados al mejoramiento o deterioro del rendimiento funcional de las defensas inmunológicas. En atención a la pandemia de COVID-19, y su mecanismo fisiopatológico plasmado en lo que se ha denominado "la tormenta de citoquinas", son especialmente relevantes aquellos patrones alimentarios que permiten modular el estado inflamatorio y el balance redox sistémico. En este sentido, el índice inflamatorio de la dieta (DII) es una medida que fue diseñada para evaluar comprensivamente el potencial inflamatorio de la dieta de un individuo sobre marcadores plasmáticos de inflamación como proteína $C$ reactiva ultra-sensible (usPCR), homocisteína, IL6, TNF $\alpha$, entre otros (Khan et al., 2020). De acuerdo con el DII, en general, dietas ricas en vegetales, frutas, antioxidantes, vitaminas y aceites ricos en ácidos grasos poliinsaturados reducen la inflamación crónica sistémica, mientras que las dietas ricas en grasas saturadas y carbohidratos simples aumentan el estado inflamatorio. Una alta puntuación en el DII, es decir un estado proinflamatorio, se ha asociado con riesgo aumentado de enfermedades cardiovasculares y presenta correlación con otros índices de alimentación saludable como el Índice de alimentación saludable - 2010 (HEI-2010) y el Índice de aproximaciones dietéticas para detener la hipertensión (DASH) (Khan et al., 2020).

Un modelo nutricional que presenta bajo potencial inflamatorio es la dieta mediterránea, caracterizada por un alto consumo de alimentos de origen vegetal como cereales, frutos secos, frutas frescas, verduras, leguminosas, nueces, semillas y aceitunas; un consumo moderado de productos lácteos, huevos, pescado y vino durante las comidas; bajo consumo de productos azucarados y carnes rojas. Además, destaca el aceite de oliva como principal fuente de lípidos (Mazzocchi et al., 2019; Barrea et al., 2020). Estudios como PREDIMED han demostrado que una dieta mediterránea suplementada con aceite de oliva o nueces está asociada a la reducción de un $28 \%$ en la incidencia de eventos cardiovasculares en personas de alto riesgo, incluyendo diabéticos (Estruch et al., 2018). El poder preventivo de la dieta mediterránea parece estar mediado por su capacidad antiinflamatoria e inmunomoduladora, la cual ha sido probada en un metaanálisis que reportó una disminución significativa en usPCR, IL6 y la molécula de adhesión intracelular 1 (ICAM1) (Schwingshackl \& Hoffmann, 2014). Un estudio no incluido en el metaanálisis, consistió en un ensayo controlado aleatorizado en pacientes con diagnóstico reciente de diabetes, realizando un seguimiento de hasta 8 años en un grupo asignado a la dieta mediterránea vs. un grupo asignado a una dieta baja en grasas. El estudio mostró 
una reducción significativa en marcadores inflamatorios solo en el grupo de dieta mediterránea (Maiorino et al., 2016). La abundancia de alimentos ricos en compuestos antioxidantes y con actividad antiinflamatoria como ácidos grasos monoinsaturados, ácidos grasos poliinsaturados omega-3, polifenoles, flavonoides, fitoesteroles, betacaroteno, vitamina $C$, vitamina $E$ y selenio; parecen estar mediando las capacidades antiinflamatorias y antioxidantes de la dieta mediterránea ya que estos compuestos han mostrado reducir la inflamación y mejorar la respuesta inmune en estudios in vivo e in vitro (Barrea et al., 2020).

Debido a su potencial inmunomodulador y antiinflamatorio, se ha propuesto que la dieta mediterránea podría ser efectiva en la prevención de la infección y/o la disminución de la severidad de sintomatología del COVID-19; sin embargo, aún no existen estudios publicados que investiguen directamente esta hipótesis (Maiorino et al., 2020). No obstante, algunos estudios previos a la pandemia sugieren que la dieta mediterránea podría disminuir la susceptibilidad a infecciones. En este sentido, el estudio REGARDS demostró que una alta adhesión a la dieta mediterránea está asociada a una disminución del $26 \%$ en el riesgo de sepsis en una población de 30.239 individuos, la cual incluyó un 20\% de diabéticos (Gray et al., 2018). Por otra parte, un estudio prospectivo realizado en 128 niños de 1 a 5 años, reportó que una dieta mediterránea de alta calidad puede mejorar la evolución de infecciones respiratorias recurrentes, incluyendo una disminución en el número de admisiones a urgencia pediátrica a causa de infecciones respiratorias y una disminución del número e intensidad de los episodios de resfrío en niños (Calatayud et al., 2017). Considerando que Chile posee en su zona central, uno de los cinco ecosistemas mediterráneos del mundo, la promoción e implementación de la dieta mediterránea podría ser una medida eficaz para estimular estilos de alimentación saludables que contribuyan a potenciar la vigilancia inmunitaria. En relación con la influencia de otros patrones alimentarios, diferentes a la dieta mediterránea, y su modulación de los síntomas de infecciones respiratorias, un estudio mostró que la adhesión a la dieta DASH puede aminorar la intensidad de los síntomas de pacientes con enfermedad pulmonar obstructiva crónica (EPOC), incluyendo disminución de la tos (Ardestani et al., 2017). Debido a que la pandemia de COVID-19 es reciente, aún no existen datos que demuestren los efectos preventivos de patrones alimentarios sobre infección y modulación de los síntomas. Sin embargo, es probable que los patrones alimentarios saludables y equilibrados, como la dieta mediterránea, capaces de modular la inflamación, la respuesta inmunológica y mejorar el perfil metabólico en general, podrían ser efectivos al menos para manejar la severidad de los síntomas de una infección con SARS CoV 2.

\section{Actividad física y sistema inmune}

Si bien la actividad física se asocia a importantes beneficios en la reducción del riesgo de desarrollar enfermedades crónicas no transmisibles y mortalidad prematura, su vinculación con el sistema inmune es más bien reciente (Nieman \&Wentz, 2019). La mayoría de la evidencia científica en relación con actividad física y sistema inmune ha sido publicada a partir de los años 90 y se divide principalmente en dos tipos de efectos: el efecto agudo y el efecto crónico de la actividad física sobre el sistema inmune, especialmente en deportistas de alto rendimiento, tales como corredores de maratones, nadadores y ciclistas, con una menor cantidad de evidencia disponible para la población en general que no presenta estos niveles de actividad física (Nieman \&Wentz, 2019). La evidencia disponible para otros tipos de actividad física, como lo son el entrenamiento de fuerza o resistencia muscular sobre el sistema inmune, presentan una escasa pero emergente evidencia científica. Más aun al considerar el efecto que han tenido las medidas asociadas a COVID-19 sobre la actividad física de la población, donde se estima que más de 4 billones de personas han adoptado medidas de aislamiento impuestas por sus gobiernos para controlar la propagación de COVID-19 en la población. Lo anterior ha generado repercusiones severas en los niveles de actividad física de la población. A continuación, revisaremos la evidencia disponible en relación con el rol que cumplen la actividad física aeróbica, su intensidad y duración como también así los ejercicios de resistencia muscular en el sistema inmune con especial énfasis en la actual pandemia de COVID-19.

\section{Actividad física aeróbica, el rol de su intensidad y duración en el sistema inmune}

Si bien el sistema inmune es altamente sensible a la actividad física, la intensidad y duración del estrés fisiológico impuesto por el movimiento de nuestro cuerpo jugarán un rol clave en definir la respuesta inmunológica (Campbell \& Turner, 2018; Nieman \& Wentz, 2019). Por ejemplo, sesiones de actividad física de intensidad moderada o vigorosa (definida como actividades que requieran más de un $60 \%$ de nuestra capacidad máxima de consumo de oxígeno) y que tengan una duración entre 40-60 minutos, producirán un efecto paralelo en nuestro sistema inmune aumentando los niveles de inmunoglobulinas, citoquinas antinflamatorias, neutrófilos, células NK, células Ty células B (Nieman \&Wentz, 2019). Durante la actividad física, se produce una importante linfocitosis, donde principalmente se observa un aumento de hasta 10-veces en la concentración de las células NK, mientras que las células T CD8 ${ }^{+}$aumentan su concentración en aproximadamente 2,5 veces (Campbell \& Turner, 2018). Sin embargo, con posterioridad a realizar actividad física, se observa una etapa de disminución de linfocitos 
circulantes, lo que ha sido erróneamente descrito como hipótesis de la "ventana abierta para infecciones", caracterizada por un efecto inmunosupresor posterior a la realización del ejercicio (Campbell \& Turner, 2018). Dentro de las primeras 2 horas posteriores al término de la actividad física, la concentración de células NK y T $\mathrm{CD}^{+}$disminuye a niveles incluso más bajos que los observados antes de realizar actividad física (Campbell \& Turner, 2018), aunque retorna a sus valores normales dentro de 24 horas. No obstante, la linfopenia transitoria posterior a la actividad física no constituye una ventana de susceptibilidad a infecciones, sino una etapa de regulación avanzada del sistema inmune, caracterizada por redistribución de grandes cantidades de células $T$ a tejidos periféricos, incluyendo mucosa, pulmones, intestino y médula ósea (Campbell \& Turner, 2018). Hoy se cuenta con evidencia que posterior a la práctica de actividad física se activa la vigilancia inmunológica para detectar células infectadas, dañadas o malignas; conduciendo a un denominado "rejuvenecimiento de nuestro sistema inmunológico" (Campbell \& Turner, 2018).

\section{El rol de la fuerza muscular y ejercicios de resistencia muscular en el sistema inmune}

A pesar de que se han cumplido cuatro décadas desde que las primeras recomendaciones de actividad física fueron generadas, solo hace algunos años que se le asignó importancia al rol fundamental que cumplen los ejercicios de resistencia muscular en la salud (Bull et al., 2020). Las actuales recomendaciones de actividad física sugieren realizar ejercicios de fuerza muscular un mínimo de 2 veces a la semana para mantener una buena salud (Bull et al., 2020). Sin embargo, la evidencia con relación a los efectos de los ejercicios de resistencia muscular sobre el sistema inmune, aún no son del todo claros. Estudios recientes sugieren que el rol de la fuerza muscular sobre el sistema inmune sería más bien indirecto, el cual actuaría principalmente sobre citoquinas antiinflamatorias (Cornish et al., 2020). Al igual que en la actividad física aeróbica, ejercicios de resistencia muscular se asocian a una reducción en biomarcadores de inflamación sistémica, incluyendo una menor concentración de IL-6, TNF-a, proteína C-reactiva y proteína amiloide A sérica; y liberación de mioquinas musculares que contribuyen a activar la vigilancia inmunológica (Sellami et al., 2018). Por otro lado, los ejercicios de resistencia muscular provocan un daño muscular caracterizado por inducción de respuesta inflamatoria por los macrófagos residentes en tejido muscular, a través de la liberación de quimioquinas que atraen a neutrófilos a la región muscular dañada. Los neutrófilos promueven un ambiente proinflamatorio mediante la secreción de interferón $\gamma$ (IFN- $\gamma$ ) y TNF-a, atrayendo a más macrófagos al tejido muscular dañado por el ejercicio de resistencia. Se distinguen dos poblaciones de macrófagos infiltrados en el tejido muscular: M1 o macrófagos proinflamatorios y M2 o macrófagos antiinflamatorios, los cuales son reclutados en forma preferencial por la secreción de IFN- $\gamma$ y IL6, respectivamente. Además, se ha descrito un reclutamiento secuencial de las dos poblaciones de macrófagos, comenzando con los M1 durante la etapa de la contracción muscular propiamente tal, lo cual marca un estado inflamatorio; y la posterior llegada de los M2 cuando ha culminado el ejercicio. Se sugiere que esta última etapa, marcada por un aumento transitorio de IL6, tendría un rol antiinflamatorio para reestablecer la homeostasis inmunológica luego de terminar el ejercicio de resistencia en individuos sanos y adaptados a este tipo de ejercicios en forma regular (Sellami et al., 2018).

\section{Actividad física y su vinculación con enfermedades infecciosas del sistema respiratorio y COVID-19}

Existe bastante evidencia de estudios de intervención que comprueban la relación entre ejercicio de corta duración ( $<1$ hora) e intensidad moderada, y el riesgo de infecciones del tracto superior del sistema respiratorio (Campbell \& Turner, 2018; Nieman \&Wentz, 2019). Metaanálisis que incluyen estudios de corta a larga duración (8 semanas a 12 meses), concuerdan que la realización de ejercicio de intensidad moderada se asocia a un riesgo $28 \%$ menor, de sufrir infecciones del tracto superior del sistema respiratorio, en personas activas versus las inactivas o con menores niveles de fitness cardiorrespiratorio (Campbell \& Turner, 2018; Nieman \& Wentz, 2019). Incluso el número de días con síntomas asociados a infecciones respiratorias fue $43 \%$ menor en personas que se ejercitaban $\geq 5$ veces a la semana (con duración entre 20 y 60 minutos por sesión), en comparación a aquellos que realizaban ejercicio $\leq 1$ vez a la semana (Campbell \& Turner, 2018; Nieman \& Wentz, 2019) (Figura 5). Estudios longitudinales han reportado que personas inactivas, o con bajos niveles de fitness cardiorrespiratorio, presentan un mayor riesgo de desarrollar enfermedades respiratorias y morir a causa de estas. En comparación a personas con niveles normales de fitness, aquellas en el cuartil más bajo de fitness, presentaron un riesgo 98\% mayor de morir por enfermedad pulmonar obstructiva crónica (Steell et al., 2019). Esta evidencia es aplicable a la actual pandemia de COVID-19 donde la actividad física y mantención del fitness cardiorrespiratorio se asocia a un menor riesgo de desarrollar sintomatología severa asociada al COVID-19 o morir por su causa (Hamer et al., 2020). Por ende, mantener la práctica regular de actividad física y un buen fitness cardiorrespiratorio reduciría el riesgo de sufrir una infección severa por COVID-19 en un 32\% en comparación a las personas inactivas (Hamer et al., 2020). 


\section{El estrecho vínculo entre función pulmonar, actividad física, obesidad y COVID-19}

El actual desafío sanitario asociado al COVID-19 en el mundo, ha llevado a replantear el rol que juega la actividad física y el tener una buena condición física en la disminución del riesgo de desarrollar síntomas severos de COVID-19 (Figura 3), los cuales podrían desencadenar la muerte. Un estudio reciente de factores modificables asociados al COVID-19 realizado en población británica, identificó al ritmo de caminata y los marcadores de capacidad pulmonar FEV1 y FEC, como importantes predictores de riesgo en el desarrollo de síntomas severos de COVID-19 (Figura 3) (Ho, 2020). Personas con un ritmo de caminata lento presentaron un 104\% mayor riesgo de desarrollar síntomas severos de COVID-19, en comparación a personas con un ritmo de caminata normal, mientras que el aumento de una unidad de FEV1 y FEC, se asoció a un 18\% y $17 \%$ menor riesgo de desarrollar síntomas severos de COVID-19, respectivamente (Ho, 2020) (Figura 3). Considerando que estos tres marcadores presentan una fuerte correlación positiva con los niveles de actividad física, fuerza muscular y fitness cardiorrespiratorio (Figura 3), es importante mantener una buena condición cardiorrespiratoria, a través de la práctica regular de actividad física y ejercicios de resistencia muscular, ya que esta se asociará directamente con un incremento en nuestra capacidad funcional pulmonar (FEC1 y FEC). Sin embargo, hay otros factores de riesgo como el exceso de adiposidad, que podrían aminorar los beneficios de un alto fitness cardiorrespiratorio y capacidad pulmonar (Figura 3). Por esto, es importante que durante esta pandemia del COVID-19, se promueva la importancia que las personas se mantengan físicamente activas. Si bien, actividades grupales no se recomiendan por el riesgo de aumentar la propagación del virus COVID-19, actividades relacionadas al transporte activo, como el caminar a un paso rápido, andar en bicicleta, o actividades como correr o subir escaleras, podrían ser alternativas viables para mantener o incrementar nuestro fitness cardiorrespiratorio y capacidad funcional, disminuyendo el riesgo de infección severa por COVID-19.

\section{Actividad física, vacunación y sistema inmune}

La vacunación permite inducción de la respuesta inmune adquirida sin experimentar la enfermedad. Al respecto, ha habido un gran interés por entender si actividad física podría mejorar la respuesta de nuestro sistema inmune, especialmente en personas mayores (Pascoe et al., 2014; Campbell \&Turner, 2018). Un reciente metaanálisis que incluyó 8 estudios de intervención, concluyó que realizar actividad física antes de la administración de una vacuna mejoraría la respuesta de nuestro sistema inmune significativamente (Pascoe et al., 2014). Por ejemplo, en personas mayores de 60 años, y que además son una de las poblaciones objetivo de los programas de vacunación, existe evidencia que aquellos que son físicamente activos presentan una mayor concentración plasmática de lgG, IgM y células mononucleares en comparación a sus pares inactivos (De Araujo, 2020). Nuevos hallazgos en modelos animales han reportado que animales que se someten entre 20-30 minutos de actividad física, 4 horas después de la administración de una vacuna intranasal para la influenza, presentaron mayor sobrevivencia (un 82\% sobrevivió), en comparación a aquellos que recibieron la misma vacuna, pero que no fueron sometidos a actividad física (solo un $43 \%$ sobrevivió) (Lowder et al., 2005).

\section{Actividad física en espacios cerrados, el sistema inmune y el riesgo de infección}

Si bien sabemos que la mejor forma de prevenir infecciones es mantener una buena higiene y hábitos de vida saludable, existen entornos deportivos que podrían aumentar nuestro riesgo de desarrollar una infección. Una de las formas más comunes de entrenamiento en la sociedad actual incluye la actividad física realizada en espacios cerrados, específicamente en gimnasios. Si bien la actividad física se asocia a importantes beneficios en salud, el realizar este tipo de actividades en espacios cerrados y de alta demanda, se ha asociado a un aumento del riesgo de desarrollar enfermedades infecciosas del sistema respiratorio, como la influenza y tuberculosis (Andrade et al., 2018). El riesgo de contraer este tipo de infecciones aumenta significativamente durante las tardes, donde existe una mayor demanda de estos recintos y los sistemas de ventilación e higiene no son muchas veces los más adecuados (Andrade et al., 2018), destacando la importancia de mantener ventilación e higiene adecuada, como también limitar la densidad usuaria, especialmente en horas punta (Andrade et al., 2018).

\section{Conclusión}

El sistema inmune cumple un rol esencial en la mantención de nuestra salud. No obstante, ciertos estilos de vida pueden contribuir a mantener nuestras defensas en un estado óptimo, disminuir el riesgo de contraer infecciones y aminorar la sintomatología de algunas infecciones respiratorias. Esta revisión ha destacado los factores clave en la alimentación, nutrición y actividad física, que nos permitirían mantener nuestro sistema inmune en un estado funcional óptimo, como también hemos destacado que cierto tipo de actividades, como deportes supra máximos y la realización de actividad física en espacio cerrados y con una inadecuada ventilación e higiene, podrían propiciar el desarrollo de infecciones en los usuarios. Entregar evidencia que permita contextualizar el rol de la alimentación y actividad física en los tiempos en los que estamos viviendo es clave, sobre todo si consideramos que más de 4 billones de personas han sido puestas en aislamiento a nivel mundial, lo cual ha repercutido severamente en los estilos de vida, incluyendo 
adopción de una alimentación menos saludable y reducción de los niveles de actividad física de la población en aislamiento, lo cual, como se presentó en esta revisión podría tener importantes implicaciones en el sistema inmunológico y por ende, en la respuesta de nuestro organismo ante amenaza impuesta por el COVID-19.

\section{Contribuciones}

El trabajo no tuvo financiamiento. Los autores declaran no tener conflicto de interés.

\section{Referencias}

Abbas A, Lichtman A \& Pillai S. (2017). Cellular and Molecular Immunology. (Elsevier) (9th ed).

Andrade A, Dominski FH, Pereira ML, de Liz CM \& Buonanno G. (2018). Infection risk in gyms during physical exercise. Environ Sci Pollut Res Int 25, 19675-19686.

Ardestani ME, Onvani S, Esmailzadeh A, Feizi A \& Azadbakht L. (2017). Adherence to Dietary Approaches to Stop Hypertension (DASH) Dietary Pattern in Relation to Chronic Obstructive Pulmonary Disease (COPD): A Case-Control Study. J Am Coll Nutr 36, 549-555.

Barrea L, Muscogiuri G, Frias-Toral E, Laudisio D, Pugliese G, Castellucci B, Garcia-Velasquez E, Savastano S \& Colao A. (2020). Nutrition and immune system: from the Mediterranean diet to dietary supplementary through the microbiota. Crit Rev Food Sci Nutr, 1-25.

Bull FC, Al-Ansari SS, Biddle S, Borodulin K, Buman MP, Cardon G, Carty C, Chaput J-P, Chastin S, Chou R, Dempsey PC, DiPietro L, Ekelund U, Firth J, Friedenreich CM, Garcia L, Gichu M, Jago R, Katzmarzyk PT, Lambert E, Leitzmann M, Milton K, Ortega FB, Ranasinghe C, Stamatakis E, Tiedemann A, Troiano RP, van der Ploeg HP, Wari V \& Willumsen JF. (2020). World Health Organization 2020 guidelines on physical activity and sedentary behaviour. British Journal of Sports Medicine 54, 1451-1462.

Calatayud FM, Calatayud B, Gallego JG, Gonzalez-Martin C \& Alguacil LF. (2017). Effects of Mediterranean diet in patients with recurring colds and frequent complications. Allergol Immunopathol (Madr) 45, 417-424.

Campbell JP \& Turner JE. (2018). Debunking the Myth of Exercise-Induced Immune Suppression: Redefining the Impact of Exercise on Immunological Health Across the Lifespan. Front Immunol 9, 648.
Cheikh Ismail L, Osaili TM, Mohamad MN, Al Marzouqi A, Jarrar AH, Abu Jamous DO, Magriplis E, Ali HI, Al Sabbah H, Hasan H, AlMarzooqi LMR, Stojanovska L, Hashim M, Shaker Obaid RR, Saleh ST \& AI Dhaheri AS. (2020). Eating Habits and Lifestyle during COVID-19 Lockdown in the United Arab Emirates: A Cross-Sectional Study. Nutrients 12.

Cornish SM, Chilibeck PD \& Candow DG. (2020). Potential Importance of Immune System Response to Exercise on Aging Muscle and Bone. Curr Osteoporos Rep 18, 350-356.

de Araujo AH, de Souza, J, da Silva-Maia, JK, de Lima BL. \& Sousa T. (2020). Nutritional status, diet and viral respiratory infections: perspectives for severe acute respiratory syndrome coronavirus 2. Br J Nutr 26.

Di Renzo L, Gualtieri P, Pivari F, Soldati L, Attina A, Cinelli G, Leggeri C, Caparello G, Barrea L, Scerbo F, Esposito E \& De Lorenzo A. (2020). Eating habits and lifestyle changes during COVID-19 lockdown: an Italian survey. J Transl Med 18, 229.

Estruch R, Ros E, Salas-Salvado J, Covas MI, Corella D, Aros F, Gomez-Gracia E, Ruiz-Gutierrez V, Fiol M, Lapetra J, Lamuela-Raventos RM, Serra-Majem L, Pinto X, Basora J, Munoz MA, Sorli JV, Martinez JA, Fito M, Gea A, Hernan MA, Martinez-Gonzalez MA \& Investigators PS. (2018). Primary Prevention of Cardiovascular Disease with a Mediterranean Diet Supplemented with Extra-Virgin Olive Oil or Nuts. N Engl J Med 378, e34.

Frei R, Akdis M. \& O'Mahony L. (2015). Prebiotics, probiotics, synbiotics, and the immune system: experimental data and clinical evidence. Curr Opin Gastroenterol 31, 153-158.

Gardner E. (2014). Immunology and Immune Disease. Nutrition and Immunity. Wiley \& Sons.

Gombart AF, Pierre A \& Maggini S. (2020). A Review of Micronutrients and the Immune System-Working in Harmony to Reduce the Risk of Infection. Nutrients 12.

Gray MS, Wang HE, Martin KD, Donnelly JP, Gutierrez OM, Shikany JM \& Judd SE. (2018). Adherence to Mediterranean-style diet and risk of sepsis in the REasons for Geographic and Racial Differences in Stroke (REGARDS) cohort. Br J Nutr 120, 1415-1421.

Hamer M, Kivimaki M, Gale CR \& Batty GD. (2020). Lifestyle risk factors, inflammatory mechanisms, and COVID-19 hospitalization: A community-based cohort study of 387,109 adults in UK. Brain Behav Immun 87, 184-187. 
Hiemstra PS, Amatngalim GD, Van der Does AM \& Taube C. (2016). Antimicrobial Peptides and Innate Lung Defenses: Role in Infectious and Noninfectious Lung Diseases and Therapeutic Applications. Chest 149, 545-551.

Hill C, Guarner F, Reid G, Gibson GR, Merenstein DJ, Pot B, Morelli L, Canani RB, Flint HJ, Salminen S, Calder PC \& Sanders ME. (2014). Expert consensus document. The International Scientific Association for Probiotics and Prebiotics consensus statement on the scope and appropriate use of the term probiotic. Nat Rev Gastroenterol Hepatol 11, 506-514.

Ho FK, Celis-Morales CA, Gray SR, Katikireddi SV, Niedzwiedz CL \& Hastie C. (2020). Modifiable and non-modifiable risk factors for COVID-19: results from UK Biobank. medRxiv.

Huang C, Wang Y, Li X, Ren L, Zhao J, Hu Y, Zhang L, Fan G, Xu J, Gu X, Cheng Z, Yu T, Xia J, Wei Y, Wu W, Xie X, Yin W, Li H, Liu M, Xiao Y, Gao H, Guo L, Xie J, Wang G, Jiang R, Gao Z, Jin Q, Wang J \& Cao B. (2020). Clinical features of patients infected with 2019 novel coronavirus in Wuhan, China. Lancet 395, 497-506.

Junaid K, Ejaz H, Abdalla AE, Abosalif KOA, Ullah MI, Yasmeen $\mathrm{H}_{\text {, }}$ Younas S, Hamam SSM \& Rehman A. (2020). Effective Immune Functions of Micronutrients against SARS-CoV-2. Nutrients 12.

Khan I, Kwon M, Shivappa N, J RH \& Kim MK. (2020). Proinflammatory Dietary Intake is Associated with Increased Risk of Metabolic Syndrome and Its Components: Results from the Population-Based Prospective Study. Nutrients 12.

Li T, Zhang Y, Gong C, Wang J, Liu B, Shi L \& Duan J. (2020). Prevalence of malnutrition and analysis of related factors in elderly patients with COVID-19 in Wuhan, China. Eur J Clin Nutr 74, 871-875.

Lowder T, Padgett DA \& Woods JA. (2005). Moderate exercise protects mice from death due to influenza virus. Brain Behav Immun 19, 377-380.

Mahmoudi M. \& Rezaei N. (2019). Nutrition and Immunity. Springer. Maiorino MI, Bellastella G, Longo M, Caruso P \& Esposito K. (2020). Mediterranean Diet and COVID-19: Hypothesizing Potential Benefits in People With Diabetes. Front Endocrinol (Lausanne) 11, 574315.

Maiorino MI, Bellastella G, Petrizzo M, Scappaticcio L, Giugliano D \& Esposito K. (2016). Anti-inflammatory Effect of Mediterranean Diet in Type 2 Diabetes Is Durable: 8-Year Follow-up of a Controlled Trial. Diabetes Care 39, e44-45.

Mak JWY, Chan FKL \& Ng SC. (2020). Probiotics and COVID-19: one size does not fit all. Lancet Gastroenterol Hepatol 5, 644-645.
Mazzocchi A, Leone L, Agostoni C \& Pali-Scholl I. (2019). The Secrets of the Mediterranean Diet. Does [Only] Olive Oil Matter? Nutrients 11.

Morais AHA, Aquino JS, da Silva-Maia JK, Vale SHL, Maciel BLL \& Passos TS. (2020). Nutritional status, diet and viral respiratory infections: perspectives for severe acute respiratory syndrome coronavirus 2. Br J Nutr, 1-12.

Nieman DC \& Wentz LM. (2019). The compelling link between physical activity and the body's defense system. J Sport Health Sci 8, 201-217.

Pascoe AR, Fiatarone Singh MA \& Edwards KM. (2014). The effects of exercise on vaccination responses: a review of chronic and acute exercise interventions in humans. Brain Behav Immun 39, 33-41.

Petermann-Rocha F, Hanlon P, Gray SR, Welsh P, Gill JMR, Foster H, Katikireddi SV, Lyall D, Mackay DF, O'Donnell CA, Sattar N, Nicholl BI, Pell JP, Jani BD, Ho FK, Mair FS \& Celis-Morales C. (2020). Comparison of two different frailty measurements and risk of hospitalisation or death from COVID-19: findings from UK Biobank. BMCMed 18, 355.

Petrilli CM, Jones SA, Yang J, Rajagopalan H, O'Donnell L, Chernyak Y, Tobin KA, Cerfolio RJ, Francois F \& Horwitz LI. (2020). Factors associated with hospital admission and critical illness among 5279 people with coronavirus disease 2019 in New York City: prospective cohort study. BMJ 369, m1966.

Schwingshackl L \& Hoffmann G. (2014). Mediterranean dietary pattern, inflammation and endothelial function: a systematic review and meta-analysis of intervention trials. Nutr Metab Cardiovasc Dis 24, 929-939.

Sellami M, Gasmi M, Denham J, Hayes LD, Stratton D, Padulo J \& Bragazzi N. (2018). Effects of Acute and Chronic Exercise on Immunological Parameters in the Elderly Aged: Can Physical Activity Counteract the Effects of Aging? Front Immunol 9, 2187.

SinghalT. (2020). A Review of Coronavirus Disease-2019 (COVID-19). Indian J Pediatr 87, 281-286.

Steell L, Ho FK, Sillars A, Petermann-Rocha F, Li H, Lyall DM, Iliodromiti S, Welsh P, Anderson J, MacKay DF, Pell JP, Sattar N, Gill JM, Gray SR \& Celis-Morales CA. (2019). Dose-response associations of cardiorespiratory fitness with all-cause mortality and incidence and mortality of cancer and cardiovascular and respiratory diseases: the UK Biobank cohort study. Br J Sports Med 53, 1371-1378.

Weyh C, Kruger K \& Strasser B. (2020). Physical Activity and Diet Shape the Immune System during Aging. Nutrients 12. 